\title{
Social and relational identification as determinants of care workers' motivation and well-being
}

\author{
Kirstien Bjerregaard ${ }^{1}$, S. Alexander Haslam ${ }^{2 *}$, Thomas Morton ${ }^{1}$ and Michelle K. Ryan ${ }^{1}$ \\ ${ }^{1}$ School of Psychology, University of Exeter, Exeter, UK, ${ }^{2}$ School of Psychology, University of Queensland, Brisbane, QLD, \\ Australia
}

A growing body of research in the field of health and social care indicates that the quality of the relationship between the person giving care and the person receiving it contributes significantly to the motivation and well-being of both. This paper examines how care workers' motivation is shaped by their social and relational identification at work. Survey findings at two time points ( $T 1, N=643$; T2, $N=1274$ ) show that care workers' motivation increases to the extent that incentives, the working context (of residential vs. domiciliary care), and the professionalization process (of acquiring vs. not acquiring a qualification) serve to build and maintain meaningful identities within the organization. In this context care workers attach greatest importance to their relational identity with clients and the more they perceive this as congruent with their organizational identity the more motivated they are. Implications are discussed with regard to the need to develop and sustain a professional and compassionate workforce that is able to meet the needs of an aging society.

Keywords: care work, motivation, social identity, organizational identity, relational identity

\section{Introduction}

School of Psychology, University of Queensland, Brisbane, QLD 4072,

Australia

a.haslam@uq.edu.au

Specialty section:

This article was submitted to Psychology for Clinical Settings, a section of the journal

Frontiers in Psychology

Received: 02 June 2015 Accepted: 11 September 2015

Published: 15 October 2015

Citation:

Bjerregaard K, Haslam SA, Morton T and Ryan MK (2015) Social and relational identification as determinants of care workers

motivation and well-being.

Front. Psychol. 6:1460.

doi: 10.3389/fpsyg.2015.01460

In the UK as elsewhere across the industrialized world, the rapidly aging population has led to a dramatic increase in the size of the adult social care workforce and this is increasingly recognized as an important social and economic resource (Centre for Workforce Intelligence, 2011; Care Quality Commission, 2012; Department of Health, 2012; Skills for Care, 2012, 2013c). In the UK, for example, the direct economic value of the adult social care sector is estimated to be worth more than $£ 20$ billion per year. The sector employees over 1.5 million people - which is more than either the construction industry or the public administration and defense sectors (Skills for Care, 2013b). Moreover, this sector is predicted to grow to employ between 2.1 and 3.1 billion people by 2025 (Centre for Workforce Intelligence, 2011). Nevertheless, with some notable exceptions, very little research has looked in any depth at the substrates of care workers' motivation or at what sustains their capacity to deliver professional and compassionate care (Help the Aged, 2007; Lucas et al., 2008; Hussein et al., 2010; Adamson et al., 2012).

The conundrum of care worker motivation is exemplified by the fact that in spite of their low status and poor financial reward, domiciliary, and care home workers report high levels of job satisfaction, pride and well-being (Cameron and Moss, 2007; Skills for Care, 2007; Lucas et al., 2009; Hussein et al., 2010). This is largely attributed to care workers' intrinsic satisfaction with their work. Indeed, in this context financial and altruistic incentives are frequently cited as polarized aspects of carers' motivation - such that the "virtuous reward" of caring (Heyes, 2005, p. 1) is often viewed 
as compensating for, and even justifying, the lack of financial reward (Heyes, 2005; Equality and Human Rights Commission, 2012).

More recently, though, there have been calls for theories to challenge the dominant social discourse that quality of caring is shaped by whether it is done 'for love' or 'for money', and to instead consider how virtuous and financial reward might be integrated aspects of care workers motivation (Nelson and Folbre, 2006; Lepore, 2008; Hussein et al., 2010; Weicht, unpublished). However, as noted in a review of the role of reward and incentives in adult social care in England (conducted on behalf of Skills for Care, 2007), although at a common-sense level one might conclude that there are links between pay, other incentives, and the recruitment and retention of care workers, to date very little work has explored these linkages (Lucas et al., 2008).

In what work there has been on this topic, care workers' motivation has consistently been found to be associated with their relationships with clients (Skills for Care, 2007; Lucas et al., 2009; Maben et al., 2012; Adams and Sharp, 2013; Bjerregaard et al., in press a). Moreover, the quality of this relationship is also perceived (by clients and their families) to be indicative of the quality of care (Bowers et al., 2001; Wilson et al., 2009). The centrality of this relationship to the motivation and wellbeing of care workers and clients alike has also underpinned the drive for a relationship-centered approach to health and social care (Beach and Inui, 2006; Nolan et al., 2006) and the creation of compassionate care-work cultures (Adamson et al., 2012; Department of Health, 2012; Onyett, 2012; Dewar and Nolan, 2013). As yet, though, there has been little consideration of the psychological processes through which these work relationships contribute to care workers' motivation.

The context in which the carers work is also likely to shape their motivation. Long-term adult care usually takes place either in residential and nursing homes or in the form of domiciliary care in people's homes. In the former, carers work together to look after a number of residents, whereas in the latter carers typically visit people in their own homes and work independently. The two domains thus require different working styles and often attract people seeking different things from their work (Care Quality Commission, 2012; Bjerregaard et al., in press a). Accordingly, the implications of working in these different domains for motivation also needs to be taken into account when considering how best to create and sustain compassionate care organizational cultures.

In both spheres of activity, the ongoing professionalization of the sector over the last decade, in the UK and elsewhere, has resulted in the establishment of standards for workforce training and qualifications, the regulation of care practices, and the accountability of the sector to a professional body. Many discussions around this issue emphasize the importance of employee training and qualifications (e.g., Department of Health, 2006, 2012; Wild et al., 2010) and studies have found that care workers themselves identify training and development as important determinants of their work motivation (Wild et al., 2010; Skills for Care, 2013a,c). Again, though, very little, if any, research has examined whether and how training relates to the other motivational factors that sustain workers in the care sector. It is therefore pertinent to examine whether care workers' pursuit and acquisition of qualifications enhances their motivation at work, and how this relates to other psychological outcomes such as well-being.

\section{Understanding Care Workers' Motivation}

As noted above, mainstream accounts of employee motivation foreground individualistic considerations and argue that work motivation is driven primarily by personal self-interest or the trade-off between money and altruistic reward. Accounts that go beyond a simple focus on economic (vs. other) reward nonetheless also theorize motivation as largely the outcome of personal factors. For example, self-determination theory (SDT; Ryan and Deci, 2000; Gagné and Deci, 2005) distinguishes between different types of motivation on a continuum between extrinsic controlled, "amotivation (which is wholly lacking in self-determination), to intrinsic [autonomous] motivation, which is invariantly, self-determined" (Gagné and Deci, 2005, p. 335). Pertinent to this distinction, a key finding is that incentives that activate extrinsic controlled motivation (e.g., those which set financial or processing targets) can actually erode intrinsic motivations and individual satisfaction (e.g., Deci, 1972). Indeed, on the basis of this argument, Heyes (2005) proposes an economic model in which "a badly paid nurse is a good nurse" (p. 1). At the same time, individuals are understood to differ in the degree to which behavior is externally regulated vs. integrated into the personal self, and this is also seen to vary as a function of context. Nevertheless, theorizing has yet to fully account for the psychological process through which this takes place (Greguras and Diefendorff, 2009; Kovjanic et al., 2012).

In contrast to these individually oriented accounts of motivation, the social identity approach offers an alternative framework which suggests that different levels of identity enactment might contribute to creating a (compassionate) working culture. This approach combines social identity theory (SIT; Tajfel and Turner, 1979) and self-categorization theory (SCT; Turner, 1985; Turner et al., 1987), and, alongside organizational identity theory (Ashforth and Mael, 1989; Ashforth et al., 2008), focuses on the ways in which a person's work motivation is shaped both (a) by their sense of identification with different groups within an organization (Haslam et al., 2000; Van Knippenberg, 2000; Ellemers et al., 2004), and (b) by their identification with different role relationships (Sluss and Ashforth, 2008). Rather than defining the self in purely personal terms (as 'I' and ' $m e$ ') this perspective argues that the self can also be defined in collective terms (as 'we' and 'us'). So in addition to their idiosyncratic personal identity, a person's self-concept is also understood to incorporate a range of social identities and role relational identities that become more or less salient depending on the fit and accessibility of the identity within a particular context (Oakes et al., 1994).

The definition of the self at collective and relational levels has distinct implications for individual motivation and behavior because it serves to redefine the nature of the self that is implicated in processes of self-actualization and 
self-enhancement (Turner, 1985; Haslam et al., 2000; Ellemers et al., 2004; Haslam, 2004; Sluss and Ashforth, 2008). Thus when group or role-based identities are salient, as is often the case in work contexts (Haslam, 2004), a person can be driven as much by a desire to enhance a collective sense of self (e.g., as a woman, a care worker, or an employee of a given organization) as they are by a desire to enhance their relational sense of self (e.g., in their role as supervisor or carer) or their personal sense of self (as a unique individual; e.g., Tim, Mary). In a range of circumstances this also means that acting in the interests of group membership can override concerns about personal selfinterest (Onorato and Turner, 2001). As Ellemers et al. (2004, p. 461) assert "self-conception in collective terms would energize people to exert themselves on behalf of the group, facilitate the direction or effort toward collective (instead of individual) outcomes and help workers sustain their loyalty to the team or organization through times when this is not individually rewarding."

Speaking to the value of this approach, a broad body of research has shown that organizational identification is positively related to a range of work-related attitudes and behaviors such as motivation, performance, job satisfaction, turnover intentions, and absenteeism (for reviews, see Tyler and Blader, 2000; Van Knippenberg, 2000; Haslam, 2004; Riketta and Van Dick, 2005). More recent organizational research on the strength of identification with different foci of attachment has also found that people typically indicate greater levels of identification with localized identities such as teams (Riketta and Van Dick, 2005; Riketta and Nienaber, 2007) and role relationships (Sluss et al., 2012; Smith et al., 2012) than with the organization as a whole. At the same time, organizational identification is often the strongest predictor of work-related outcomes including motivation and well-being (Sluss et al., 2012; Smith et al., 2012; for a general discussion of the relationship between social identification and well-being, see Haslam et al., 2009; Jetten et al., 2012). Accordingly, to the extent that their identification with different work relationships and work groups is congruent with, or nested within, organizational identification, then one would expect workers to be more motivated and more satisfied at work (Van Knippenberg, 2000; Haslam et al., 2003; Ellemers et al., 2004; Wegge et al., 2006; Riketta and Nienaber, 2007; Ashforth et al., 2008; Akerlof and Kranton, 2010). This is because, in instances of such perceived alignment, by advancing the organization the individual will see themselves to be enhancing aspects of the (collectively defined) self. On the other hand, when they experience incongruence between their role relationships and their team or organization, people are likely to be less motivated and experience compromised well-being in the form of greater frustration and stress (Haslam and Reicher, 2006).

According to Sluss and Ashforth (2008), congruence between relational and collective identities is likely to be strengthened by (1) the degree of task interdependence (a particularly high level of which is evident between frontline care workers and clients; Karlsson and Rydwik, 2013); and (2) the degree to which the relational partner is prototypical of the organization or the working context. In line with this reasoning, it seems likely that whether care workers indicate strong relational identification with their clients and whether their client and organizational identities converge will depend on the extent to which the care worker perceives their caring role with the client to be supported by the organization.

\section{The Present Research}

To take into account the social and relational context in which care work takes place, the present research seeks to examine the motivation of care workers through the lens of social identity theorizing. In particular, it seeks to investigate the link between what incentivizes people to work in adult social care and their motivation and well-being. More specifically, it seeks to explore the role of financial incentives and social relationships in motivating care workers and driving positive work-related experiences (e.g., greater job satisfaction, reduced stress). Here, rather than dichotomising the 'love' and 'money' aspects of working in care we argue that they will form integrated elements of care workers' motivation to the extent they serve to build meaningful work-based identification.

In addition, this study also examines how care workers' motivations and well-being might be influenced by the two different working domains in which care workers predominately operate and by the process of professionalization, (i.e., undertaking qualifications). In line with recommendations about how to apply social identity analysis in the field (Haslam et al., 2003; Haslam, 2014) the study also focuses on those work identities that were identified as self-relevant by care workers in previous qualitative work in the present program (Bjerregaard et al., in press b) - namely client, care staff, care professional, and organization identities.

\section{Hypotheses}

Based on the above reasoning, this study sought to test five main hypotheses:

- H1. Care workers' social identification with different groups at work will be positively related to their work motivation and well-being (Ellemers et al., 2004). Specifically, we expect that carers' work motivation and well-being - that is, their pride, job satisfaction, and stress, as well as their job attachment (turnover intentions and pro-professionalization) - will be predicted by their identification with (a) the people they care for (client identification; H1a) and (b) the care organization they work for (organizational identification; H1b). Moreover, although care workers are (c) likely to indicate higher levels of client identification than organizational identification (H1c); their (d) organizational identification is likely to be the more proximal predictor of motivation and well-being (H1d).

- H2. Care workers will primarily be incentivized to work in care because of their caring relationship with clients (H2a). However, the extent to which valuing relationships with clients leads to higher levels of motivation and well-being at work, will be mediated by identification with the organization (H2b). Moreover, this organizational identification is expected to be predicted by client identification $(\mathrm{H} 2 \mathrm{c})$. 
- H3. Care workers will be less incentivized by pay than by other social considerations (H3a). Nevertheless, the extent to which pay does lead to increased motivation and well-being will also be mediated by organizational identification (H3b). Here the effects of organizational identity are unlikely to be predicted by client identification $(\mathrm{H} 3 \mathrm{c})$.

- H4. Carers' sense of social identity will vary as a function of their place of work (i.e., residential/nursing home or domiciliary care). The nature of independent working involved in domiciliary care will lead workers to have higher levels of client identification (H4a) and lower levels of organizational identification $(\mathrm{H} 4 \mathrm{~b})$ than those working in residential care. This lack of congruence between identities makes it more likely that domiciliary care workers will report lower levels of work motivation and well-being than those who work in residential care $(\mathrm{H} 4 \mathrm{c})$.

- H5. Undertaking a qualification is likely to lead to increased motivation and well-being (H5a). Again this is expected to be mediated by organizational identity ( $\mathrm{H} 5 \mathrm{~b})$. More specifically, the effects of undertaking a qualification on motivation and well-being should be explained by the extent to which undertaking a qualification increases and maintains identification with the organization and other groups at work (H5c).

\section{Study Context}

To test these hypotheses, we administered an organizational survey to carers at two time points, 1 year apart. The surveys were distributed across multiple sites (in different locations across the south of England) in a large care organization that had recently amalgamated a number of smaller organizations. The survey measured carers' motivation, their sense of identity at work, and their feelings about work outcomes, including professionalization. As well as allowing us to examine the relationship between these variables cross-sectionally, the study's longitudinal design also enabled us to examine variation in responses over time as a function of whether or not people had undertaken professional qualifications in the intervening period-so that, in effect, undertaking a professional qualification in the past year constituted an experimental treatment (for similar logic, see Lim and Putnam, 2010). In this way, the study had a quasi-experimental longitudinal design, which enabled us to examine the impact of exposure to professional training on organizational identification and motivation.

\section{Materials and Methods}

Surveys were administered to care staff who worked for a large not-for-profit organization that operates across the South of England and the Isle of Wight. The care organization, which recently incorporated four different care organizations, runs 28 residential care and nursing homes and delivers domiciliary care services from six domiciliary care bases. Its clients are primarily elderly people, yet services are also provided for younger people who need support to live independently on their own and in groups. The studies were conducted at two time points, 1 year apart, in January 2010 (T1) and January 2011 (T2).

\section{Participants}

Table 1 provides a detailed breakdown of sample characteristics. At Time 1, 3280 questionnaires were distributed and 643 were returned completed - a response rate of $20 \%$. The majority of participants $(n=458 ; 72 \%)$ worked in residential and nursing care (residential care), $28 \%(n=172)$ worked in domiciliary care. At Time 2, 4,200 questionnaires were distributed. Of these, 1274 completed questionnaires were returned - a $33 \%$ response rate. The majority of respondents $(58 \%, n=740)$ worked in residential care while $42 \%(n=534)$ worked in domiciliary care. The substantially higher response rate at Time 2 was primarily the result of efforts to raise awareness of the survey among care staff through an article in the organization's newsletter and presentations to managers. This had an especially notable effect in increasing the response rate of domiciliary care staff. A total of 204 carers participated on both occasions, $70 \%$ in residential care and $30 \%$ in domiciliary care. Of these, $51 \%(n=103)$ had undertaken a professional qualification over the course of the year (i.e., were exposed to a professionalization treatment) and $49 \%$ $(n=100)$ had not.

\section{Measures}

Participants completed a four-page, 51-item questionnaire, in which they indicated agreement with statements on scales ranging from 1 (strongly disagree) to 7 (strongly agree). Work motivation was measured by means of five scales that examined (a) job satisfaction (three items, $\mathrm{T} 1 \alpha=0.79, \mathrm{~T} 2 \alpha=0.76$, typical items: "I enjoy my work at [the care organization]"; after Haslam and Reicher, 2006); and (b) pride (three items, T1 $\alpha=0.71$, $\mathrm{T} 2 \alpha=0.75$, typical item: "I am proud to work in the care sector," adapted from Tyler and Blader, 2000); (c) stress (four items, reversed scored, T1 $\alpha=0.70, \mathrm{~T} 2 \alpha=0.69$; typical item:

TABLE 1 | Sample demographics.

\begin{tabular}{lccc}
\hline & Time 1 & Time 2 & Longitudinal \\
\hline No. q'res distributed & 3,280 & 4,200 & \\
No. q'res returned & 643 & 1,274 & 204 \\
Response rate & $20 \%$ & $33 \%$ & \\
\% Residential care & $72 \%$ & $58 \%$ & $70 \%$ \\
\% Domiciliary care & $28 \%$ & $42 \%$ & $30 \%$ \\
Gender & $F=571$ & $F=1077$ & $F=188$ \\
& $(92 \%)$ & $(90 \%)$ & $(92 \%)$ \\
Age range & $M=51$ & $M=124$ & $M=15$ \\
& $16-76$ & $16-78$ & $18-78$ \\
Job role & $M=44.8$, & $M=42.57$, & $M=46.62$, \\
Domestic workers & $S D=12.12$ & $S D=14.90$ & $S D=14.27$ \\
Care workers & $52(8.5 \%)$ & $124(10 \%)$ & $20(10 \%)$ \\
Snr care workers & $364(57 \%)$ & $885(69 \%)$ & $124(61 \%)$ \\
Managers & $115(18 \%)$ & $114(9 \%)$ & $27(13 \%)$ \\
Admin and planners & $43(6 \%)$ & $51(4 \%)$ & $21(10 \%)$ \\
Undisclosed role & $21(3 \%)$ & $36(3 \%)$ & $10(5 \%)$ \\
& $48(7.5 \%)$ & $64(5 \%)$ & $2(1 \%)$
\end{tabular}


"I am able to cope with the demands of my job" adapted from Haslam and Reicher, 2006); (d) turnover intentions (two items, reversed scored, T1 $r=75, \mathrm{~T} 2 r=0.72$, typical item: "I would like to stay working at [the care organization] for as long as possible"; after Ellemers et al., 1999); (e) pro-professionalization (five items, T1 $\alpha=0.76, \mathrm{~T} 2 \alpha=0.75$, typical item: "I feel positive about the process of professionalization at [the care organization]").

Key factors which incentivize carers to work for the care organization were measured by the extent to which (a) pay and (b) relationship with clients were valued. In each case, responses were given to a single item indicating whether "I work at [the care organization] primarily because I value the [incentive]." At Time 2 this measure was supplemented by an item in which respondents indicated their satisfaction with incentives by responding to statements of the form: "Overall I am satisfied with the [incentive] at [the care organization]": pay, $r=0.47$, relationship with clients, $r=0.60$.

Work identification was measured by four three-item scales that asked participants about different loci of identification in the workplace: (a) with clients (client identification); (b) with staff at the care home or domiciliary base (staff identification); (c) with care professionals (professional identification); and (d) with the organization (organizational identification). For each measure respondents indicated whether "I feel strong ties with [group]," "I feel good about [group]," "I am willing to do as much as possible to make life easy for [group]" (adapted from Doosje et al., 1995; $\mathrm{T} 1 \alpha \mathrm{s}=0.78,0.65,0.65,0.73$, respectively; T2 $\alpha \mathrm{s}=0.70,0.76$, $0.72,0.71$, respectively).

At the end of the questionnaire participants were asked to provide demographic information (age, gender, length of service working, and ethnicity), as well as information about the nature of their work, their occupational role (domestic staff, care worker, senior care worker, manager, administrator or planner), and their work domain (residential and nursing vs. domiciliary care). At Time 2 participants were asked additional questions about the amount of training days they had undertaken in the past year, whether they had undertaken professional qualification in this time, and, if so, at what level.

\section{Ethical Approval}

The research was approved by the School of Psychology Ethics Committee at the University of Exeter. This required participant anonymity and data confidentiality.

\section{Procedure}

A questionnaire containing the above scales was distributed to care staff in sealed envelopes via the care homes and domiciliary bases. Prior to administration, the questionnaire was piloted on a small sample of 15 care workers in order to check and refine its terminology and structure. Questionnaires were accompanied by a cover letter from the organization and the researchers' university that outlined the purpose of the survey and informed participants that completion of the questionnaire was taken as an indication of their consent to take part in the study, but that this was voluntary. Confidentiality and anonymity were assured. Respondents then returned the questionnaire in an enclosed stamped addressed envelope to the University. To enable questionnaires from the same person to be linked, respondents were requested to provide a unique identifying code. The recruitment of participants was intended to cast a wide net such that the sample was representative of all care workers working in domiciliary, residential and nursing care rather than any particular sub-sample.

\section{Results}

\section{Analytic Strategy}

Given the large number of respondents at T2 and the good representation of responses from domiciliary workers as well as residential care workers (that was missing from the T1 and longitudinal data), we decided to conduct our analysis on the cross-sectional T2 data and focused our analysis of longitudinal data on the changes that occurred over time, primarily around the impact of professionalization. Crosssectional analysis proceeded in two steps. First, preliminary tests of hypotheses were conducted by examining bivariate correlation between the various measures administered in the study at each time - in particular, the relationships among (a) work group identification and motivation/well-being (H1), (b) perceived incentives and motivation/ well-being ( $\mathrm{H} 2, \mathrm{H} 3)$, (c) type of care work and identification ( $\mathrm{H} 4)$, and (d) professionalization activity (undertaking a qualification) and motivation/well-being (H5).

Second, we used structural equation modeling (SEM) to test two integrated theoretical models. Model 1 examined whether different incentives to work in care, namely relationships with clients and pay, are associated with greater motivation and well-being to the extent that they build relational identification with clients $(\mathrm{H} 2 \mathrm{a})$ and through this contribute to broader organizational identity ( $\mathrm{H} 3 \mathrm{a}, \mathrm{H} 3 \mathrm{~b})$. Model 2 then considered how the care work context - in this case, care workers' work domain and their experience of having undertaken a qualification - was associated with motivation and well-being at work, and whether any effects could be accounted for by strengthened organizational identification ( $\mathrm{H} 4 \mathrm{c}$ and $\mathrm{H} 5 \mathrm{~b}$ ).

A second phase of analysis was conducted on the longitudinal data $(n=204)$ and examined variation in responses over time as a function of whether or not respondents had undertaken a qualification in the intervening period. In this analysis, having undertaken qualifications during the intervening period ( 1 year) was treated as a quasi-experimental intervention. This enabled us to assess whether undertaking a qualification had any impact on identification and, through this, motivation and well-being $(\mathrm{H} 5 \mathrm{c})$.

\section{Cross-sectional Analysis Bivariate Associations}

Mean, standard deviation, and bivariate correlation for crosssectional data at $\mathrm{T} 2$ are reported in Table 2. As can be seen from this table, participants generally reported positive work experiences and outcomes: they indicated very high levels of satisfaction, high levels of pride, and low levels of stress. They also 
TABLE 2 | Bivariate correlation, Time 2.

\begin{tabular}{|c|c|c|c|c|c|c|c|c|c|c|c|c|c|c|}
\hline & $M$ & $S D$ & $1 a$ & $1 b$ & $2 a$ & $2 b$ & $3 \mathbf{a}$ & $3 b$ & $3 c$ & 3d & $4 a$ & $4 b$ & $4 c$ & $4 d$ \\
\hline 1a Qualification taken & 1.51 & 0.50 & & & & & & & & & & & & \\
\hline 1b Working domain & 1.43 & 0.50 & $-0.08^{*}$ & & & & & & & & & & & \\
\hline \multicolumn{15}{|l|}{ Work incentive } \\
\hline 2a Pay & 3.10 & 1.46 & 0.02 & 0.03 & & & & & & & & & & \\
\hline 2b Relationship with clients & 6.02 & 0.81 & $0.07^{*}$ & $0.07^{*}$ & 0.02 & & & & & & & & & \\
\hline \multicolumn{15}{|l|}{ Work identification } \\
\hline 3a Client & 5.92 & 0.77 & 0.04 & 0.05 & $0.06^{*}$ & $0.64 * *$ & & & & & & & & \\
\hline 3b Staff & 5.37 & 0.95 & $0.10^{* *}$ & $0.09 * *$ & $0.15^{* *}$ & $0.31 * *$ & $0.46^{* *}$ & & & & & & & \\
\hline 3c Organization & 5.21 & 0.99 & $0.10^{* *}$ & $0.12^{* *}$ & $0.31 * *$ & $0.34^{* *}$ & $0.45^{* *}$ & $0.63^{* *}$ & & & & & & \\
\hline 3d Care professional & 5.29 & 0.92 & $0.11^{* *}$ & $0.14^{* *}$ & $0.17^{* *}$ & $0.34 * *$ & $0.52 * *$ & $0.73^{* *}$ & $0.62 * *$ & & & & & \\
\hline \multicolumn{15}{|c|}{ Work motivation and well-being } \\
\hline 4a Satisfaction & 6.02 & 0.87 & 0.05 & 0.04 & $0.23^{* *}$ & $0.37^{* *}$ & $0.43^{* *}$ & $0.43^{* *}$ & $0.53^{* *}$ & $0.425^{* *}$ & & & & \\
\hline 4b Pride & 5.68 & 0.97 & $0.08^{*}$ & 0.01 & $0.16^{* *}$ & $0.40^{* *}$ & $0.44^{* *}$ & $0.38^{* *}$ & $0.46^{* *}$ & $0.42 * *$ & $0.50 * *$ & & & \\
\hline 4c Stress & 2.40 & 0.85 & -0.05 & -0.01 & $0.18 * *$ & $0.20 * *$ & $0.31^{* *}$ & $0.41^{* *}$ & $0.43^{* *}$ & $-0.36^{* *}$ & $0.57^{* *}$ & $0.34 * *$ & & \\
\hline 4d Professionalization & 5.46 & 0.87 & $0.10^{* *}$ & $0.10^{* *}$ & $0.15^{* *}$ & $0.26^{* *}$ & $0.34^{* *}$ & $0.41^{* *}$ & $0.51^{* *}$ & $0.39 * *$ & $0.47^{* *}$ & $0.42^{* *}$ & $0.49^{* *}$ & \\
\hline 4e Turnover & 2.51 & 1.40 & -0.05 & $0.10 * *$ & $0.23^{* *}$ & $0.26 * *$ & $0.30 * *$ & $0.43^{* *}$ & $0.57^{* *}$ & $-0.39 * *$ & $0.56^{* *}$ & $0.40 * *$ & $0.43^{* *}$ & $0.42 * *$ \\
\hline
\end{tabular}

${ }^{* *} p<0.01$ (two-tailed), ${ }^{*} p<0.05$ (two-tailed).

reported being attached to their job, as reflected in low turnover intentions and favorable attitudes toward professionalization. As in other studies of the social care workforce (e.g., Heyes, 2005), carers attached the least value to pay and highest value to their relationships with clients as incentives for work.

In line with $\mathrm{H} 1$, participants indicated strongest identification with clients. They also identified strongly with the other staff where they worked, with care professionals in general, and with the organization itself (all mean $>5$ on a seven-point scale). As predicted by $\mathrm{H} 1$, and as demonstrated in the bivariate correlation, higher identification with different groups at work (clients, organization, staff and care professionals) was associated with higher levels of well-being, a positive orientation to professionalization, and lower turnover intentions. Inspection of the bivariate correlation also revealed a clear pattern whereby the strength of association between identification and well-being and job attachment increased as the locus of identification became inclusive (i.e., higher-level and broader) rather than exclusive (lower level and narrower). Thus, at the exclusive end of the spectrum, relational identification with clients was positively associated with satisfaction, pride and more positive attitudes toward professionalization ( $r \mathrm{~s}=0.43,0.44,0.34$, respectively; all $p s<0.01)$ and was negatively associated with stress and turnover intentions $(r s=-0.32,-0.34$, respectively; all $p s<0.01)$. However, at inclusive end of the spectrum these relationships were all stronger - such that collective identification with the organization was strongly positively correlated with satisfaction, pride, and positive attitudes toward professionalization ( $r \mathrm{~s}=0.53,0.46,0.51$, respectively; all ps $<0.01)$ and was strongly negatively correlated with stress and turnover intentions $(r s=-0.41,-0.61$, respectively; all ps $<0.01)$.

Bivariate correlation also pointed to a variable degree of association between different incentives and workers' motivation. In line with $\mathrm{H} 2$ and $\mathrm{H} 3$, these ranged from weak correlation between motivation, well-being and being incentivised by pay, to very strong correlation between motivation, well-being and being incentivised by relationships with client. More specifically, being incentivised by pay was weakly associated with increased satisfaction, pride, pro-professionalization attitudes as well as reduced stress and lower turnover intentions $(r s=0.23,0.16$, $0.15,-0.18,-0.23$, respectively; all $p s<0.01)$. However, there were stronger associations between being incentivised by relationships with clients and motivation and well-being in terms satisfaction, pride, pro-professionalization attitudes, reduced stress, and reduced turnover intentions ( $r s=0.37,0.40$, $0.26,-0.20,-0.26$, respectively; all $p s<0.01)$.

Consistent with $\mathrm{H} 4 \mathrm{a}$, undertaking domiciliary (vs. residential) care work was generally associated with stronger client identification and weaker colleague, professional, and organizational identification. Consistent with $\mathrm{H} 4 \mathrm{c}$ there were also negative associations between domiciliary care work and motivation, reflected in attitudes that were less proprofessionalization and stronger turnover intentions. However, there were no significant correlation between type of care work and measures of satisfaction, pride, and stress.

Finally, and consistent with $\mathrm{H} 5$, undertaking a qualification was positively associated with increased staff team identity, care professional identity, and organizational identity. In addition, undertaking a qualification was positively associated with key measures of motivation and well-being - notably increased pride and pro-professionalization. In sum, these patterns of association reveal relationships that are broadly consistent with our hypotheses. However, to explore these patterns of support in more detail, we conducted SEM.

\section{Structural Equation Modeling}

Two theoretical models were tested by SEM using AMOS 19 software. Model 1, presented in Figure 1, examined the relationship between what care workers reported incentivizes 


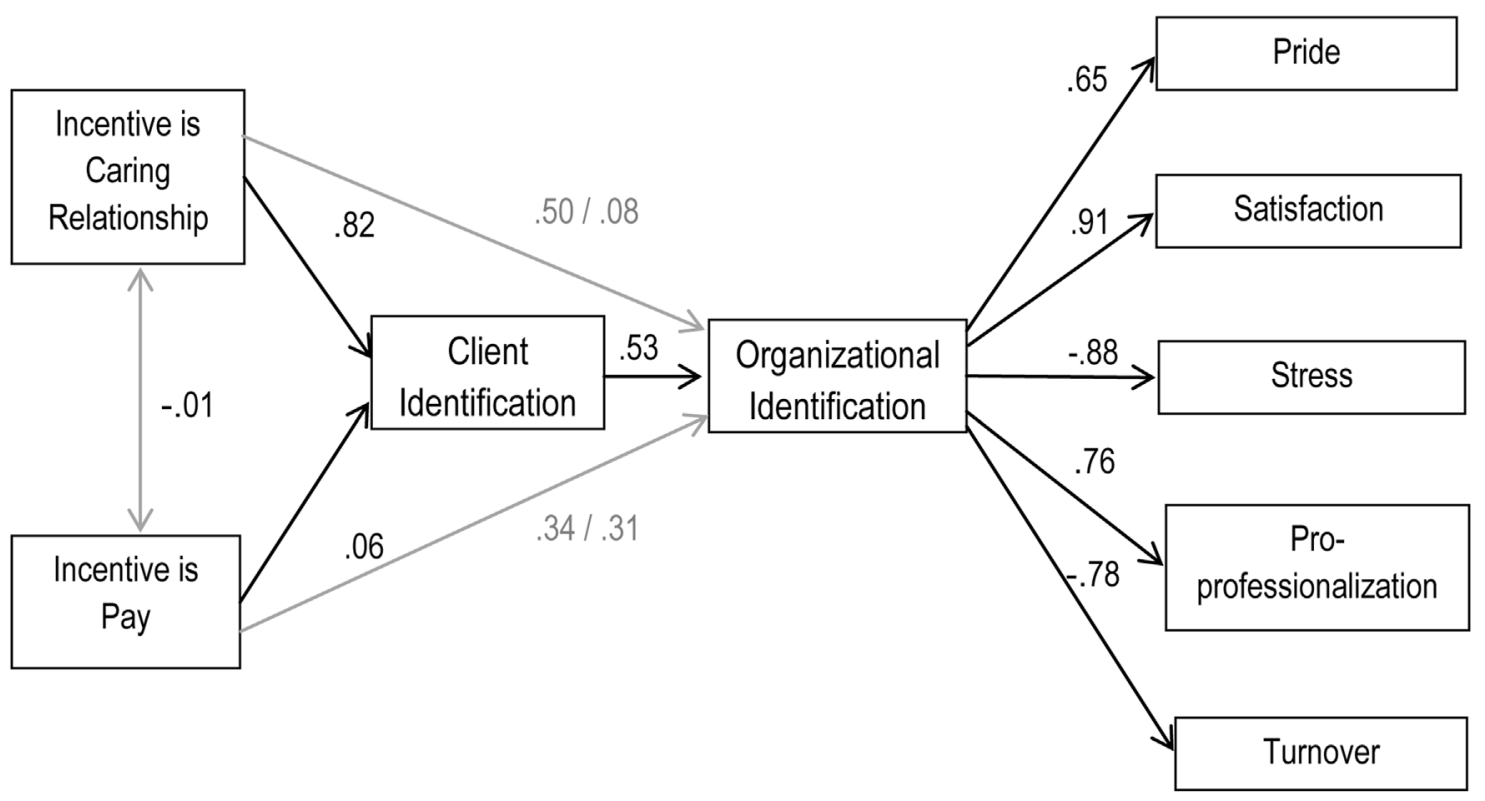

FIGURE 1 | The effects of incentive source on motivation and well-being (Model 1, Time 2).

them to work in care and their motivation and well-being at work, and the way in which this is influenced by identification with clients and the organization. Model 2, presented in Figure 2, examined whether work domain and having undertaken a qualification were related to work motivation and well-being and whether any effects that were observed were mediated by the degree to which these things strengthened (or undermined) organizational identification.

\section{Model 1}

Two sets of SEM results are reported to test Model 1: (a) the results of confirmatory factor analysis which establishes whether indicators measure the corresponding latent variables within the model and (b) the fit of the relationships outlined in the model between latent variables (following McDonald and Ho, 2002; Garson, 2009; Hayes, 2012). To determine the fit of the proposed models we report three Goodness-of Fit indices (as

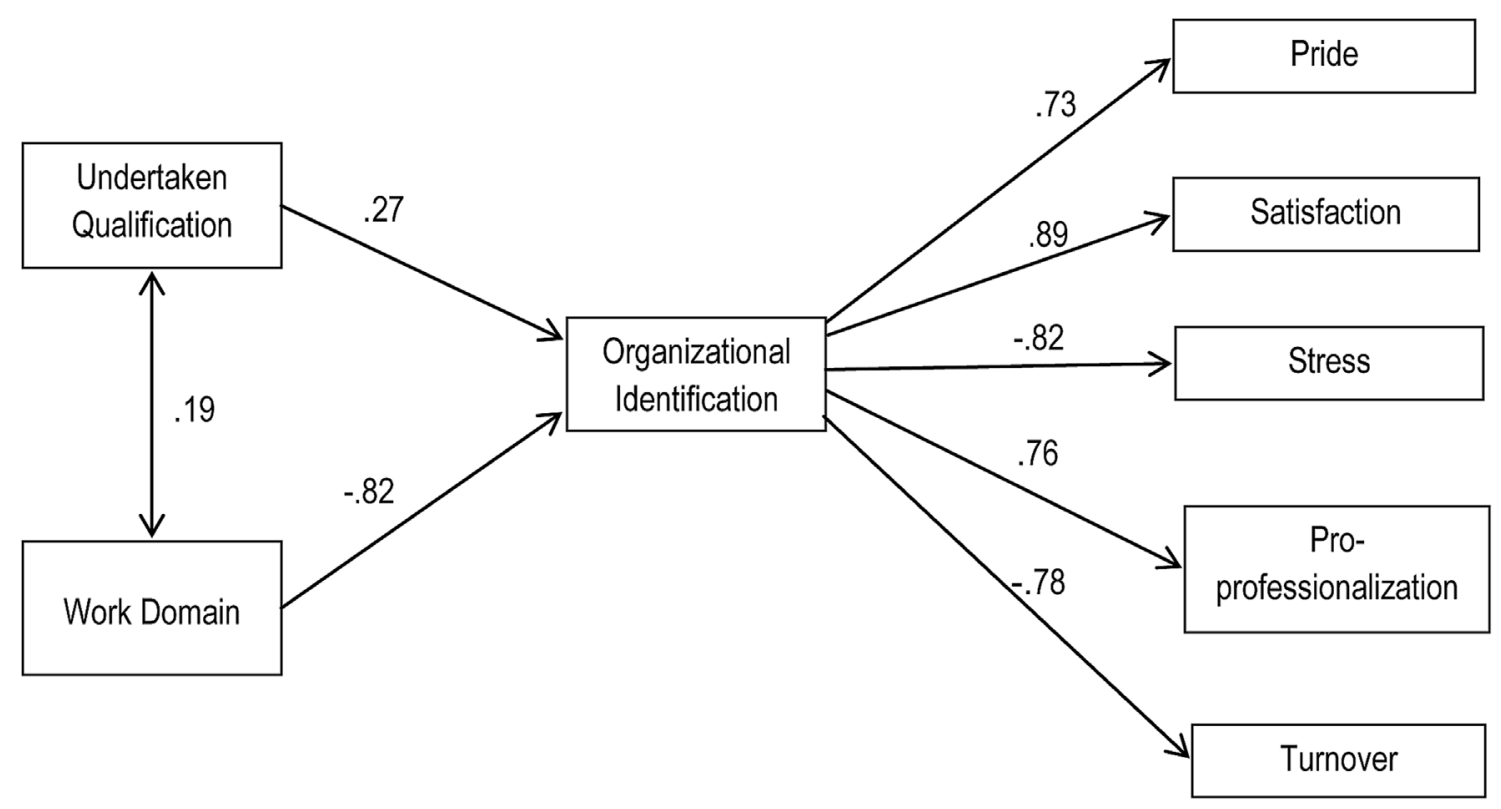

FIGURE 2 | The effects of undertaking a qualification and work domain (residential vs. domiciliary) on motivation and well-being (Model 2, Time 2). 
suggested by Garson, 2009): the chi-square $\chi^{2}$ (where values below 5 indicate an acceptable fit, values below 2 indicate a good fit); one incremental fit index, the Comparative Fit Index (CFI; where indices range from 0 to 1 , with values exceeding 0.90 indicating a good fit); and one residual fit index, the root mean squared error of approximation (RMSEA), which is based on the proportion of variance not explained in the model (where values above 0.08 indicate poor fit, above 0.05 indicate good fit, and below 0.05 indicate excellent fit; see $\mathrm{Hu}$ and Bentler, 1999, for further discussion of the appropriate application of Goodnessof-Fit indices to test Model fit; see also Garson, 2009; Kenny, 2012).

In order to provide additional support for our models, we test a null model and compare our models to plausible alternative models, which are outlined in greater detail below. The null model (where all the parameters are set to zero) tests the assumption that there is no co-variation among the variables that make up the model and provides a baseline against which to compare the theoretical model (Crabtree et al., 2010). In addition to testing this model on the largest, most representational sample (the cross-sectional data at Time 2) we further corroborated our proposed theoretical model by conducting the analysis on the longitudinal data $(n=204)$.

Confirmatory Factor Analysis validated the measurement of the model, establishing that the indicators (i.e., the items) in the model measured the corresponding latent variables (i.e., the measures), $\chi^{2}(360)=4.78$, CFI $=0.92$, RMSEA $=0.055$. As expected, the null model did not fit the data well, with a highly significant chi-square indicating a significant difference between the observed and estimated covariance matrices, $\chi^{2}(392)=38.94$, CFI $=0.001$, RMSEA $=0.18$.

The hypothesized model then tested our integrated theory (a) that the effects of incentives on organizational identity are mediated by identification with clients (H1) and (b) that what incentivises people to work in care (relationships with clients or pay) leads to enhanced motivation and well-being outcomes because it builds identification with the organization ( $\mathrm{H} 2$ and H3). The unadjusted theoretical model fitted the data well, $c^{2}(392)=5.90, \mathrm{CFI}=0.89$, RMSEA $=0.060$. In line with common practice we also examined how the fit of the model might be improved by inspecting the standardized residual matrix for highly correlated error terms and then allowing these to correlate in the model (Ullman, 1996; Crabtree et al., 2010). Highly correlated error terms were observed among indicators within a number of latent variables (organizational identification, client identification, satisfaction, stress, and proprofessionalization) and so these were allowed to correlate. This adjusted theoretical model also had a good fit to the data, $\eta_{\mathrm{p}}^{2}(405)=4.55$, CFI $=0.92$, RMSEA $=0.054$. In short, the application of this model to the data confirms its robust fit.

The fit of the adjusted theoretical model was also compared to plausible alternative models. Alternative Model A turned the hypothesized model around and examined the possibility that participants' motivation and well-being explains what it is that incentivizes them to work in care and that this is mediated by their level of client and then organizational identification. This had very poor fit to the data, $c^{2}(392)=14.89$, CFI $=0.69$, RMSEA $=0.11$. Alternative Model $\mathrm{B}$ examines a traditional economic model of motivation which suggests that people are incentivised to work in care as a function of their levels of motivation without any mediating role for processes of identification. This also had poor fit, $c^{2}(392)=13.40, \mathrm{CFI}=0.73$, RMSEA $=0.10$. Alternative Model $\mathrm{C}$ examined the possibility that organizational identification leads to client identification, and that the latter mediates the relationship between factors that incentivize participants to work in care and levels of motivation and well-being. Although it had better fit, this did not fit the data as well as the theoretical model, $\mathrm{c}^{2}(392)=6.05, \mathrm{CFI}=0.87$, RMSEA $=0.064$. In summary, our theoretical model appears to provide a better representation of our data than other models that propose plausible alternative casual sequences.

\section{Model 2}

Structural equation modeling was also used to test theoretical Model 2 - that different working domains and the process of undertaking qualifications would affect motivation and wellbeing to the extent that they serve to build organizational identification. This followed the same analytical logic as Model 1 above. Here, confirmatory factor analysis validated the measurement of the model and, as expected, the null model did not fit the data well, as evidenced by a highly significant chi-square, $\mathrm{c}^{2}(392)=43.64$, CFI $<0.001$, RMSEA $=0.186$.

The theoretical model examined the relationship between having undertaken qualifications in the last year, and subsequent motivation, and the extent to which these relationships were mediated through identification with the organization. This fitted the data substantially better than the null model and, after adjusting the model to allow a number of highly correlated items to correlate (organizational identification, satisfaction, and proprofessionalization), the amended theoretical model had good fit to the data, $c^{2}(156)=4.92, \mathrm{CFI}=0.92$, RMSEA $=0.056$. In line with recommended best practice, to test the robustness of the model we repeated it on a subsample of data comprised of those participants who took part at both times $(n=203)$. This also provided evidence of good fit.

We also tested two other plausible alternative theoretical models. Alternative Model A tested the possibility that client identification predicted organizational identification, and that both of these sequentially mediated the relationships between undertaking a qualification and working domain on the one hand and increasing well-being and motivation on the other. This model had a good fit with the data, $c^{2}(156)=5.15$, $\mathrm{CFI}=0.90$, RMSEA $=0.058$, but not as good as the theoretical model. A second plausible alternative, Model B, assessed whether undertaking a qualification and working domain led directly to increased motivation and well-being. This model had poor fit, $c^{2}(156)=10.90$, CFI $=0.82$, RMSEA $=0.090$.

\section{Longitudinal Analysis: Variation in Responses as a Function of Undertaking a Professional Qualification}

To look at the effect of time on participants' motivation we conducted an examination of the longitudinal data across T1 and 
T2 $(N=204)^{3}$. We started by conducting a paired samples $t$-test on measures of motivation and identification at the two times. In general, participants' responses were highly consistent across the year. Nonetheless, (a) participants' level of commitment rose over the course of the year, $t(197)=2.72, p<0.005$, (b) their attitude toward professionalization became more positive $t(186)=3.20, p<0.005$, (c) their identification with care professionals decreased, $t(191)=1.96, p<0.05$, (d) the value they attached to working conditions rose, $t(199)=2.02, p<0.05$, as did (e) the value they attached to opportunities for training and development, $t(198)=-2.53, p<0.05$.

Against this backdrop of evidence that there was little change in motivation and identification over the course of the year, and taking into account the pathway analysis tested in the SEM models (which demonstrated that motivational and well-being outcomes were proceeded by identification with work groups), we then tested the effects of undertaking professional qualification on identification (i.e., H5c). To this end, panel data analysis enabled us to refine our investigation and control for reverse causality and selection bias (following the strategy employed by Lim and Putnam, 2010). Here, participants' identification with care professionals was examined by mean of a 2 (Professionalization: gained vs. did not gain qualification) $\times 2$ (Phase: Time 1 vs. Time 2) ANOVA, with repeated measures on the second factor. This analysis revealed a significant effect for phase, Wilks Lambda $=0.96$, $F(1,201)=7.37, p=0.007, \eta_{\mathrm{p}}^{2}=0.04$, indicating that, as noted above, participants were less identified with care professionals at $\mathrm{T} 2(M=5.39, S D=1.0)$ than at $\mathrm{T} 1,(M=5.51, S D=0.81)$. However, this effect was conditioned by a significant interaction between professionalization and phase, Wilks Lambda $=0.97$, $F(1,201)=6.51, p=0.01, \eta_{\mathrm{p}}^{2}=0.03$. This interaction is plotted in Figure 3. Tests for simple effects revealed that there was no difference over time in the care professional identification of participants who had taken part in training between $\mathrm{T} 1(M=5.52, S D=0.81)$ and $\mathrm{T} 2(M=5.51$,

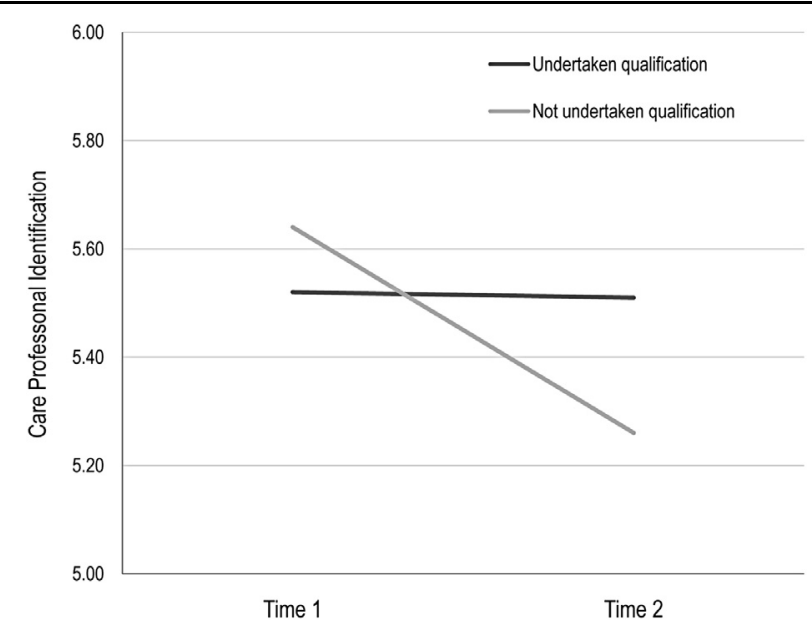

FIGURE 3 | The effects of undertaking a qualification on care professional identification, Longitudinal panel data.
$S D=0.97)$ Wilks Lambda $1.00, F(1,201)=0.02, p=0.91$, $\eta_{\mathrm{p}}^{2}=0.00$. However, there was a significant reduction in care professional identification among those who had not undertaken qualifications across these two time points (T1 $M=5.64$, $S D=0.08$; T2 $M=5.26, S D=0.09)$, Wilks Lambda $=0.94$, $F(1,201)=14.08, p<0.001, \eta_{\mathrm{p}}^{2}=0.06$.

The same analysis was performed for the measure of participants' identification with the organization. This revealed no main effect for phase [Wilks Lambda $=0.99, F(1,201)=0.10$, $p=0.75$ ] but a significant interaction between professionalization and phase, Wilks Lambda $=0.97, F(1,201)=3.83, p=0.03$, $\eta_{\mathrm{p}}^{2}=0.02$. This interaction is plotted in Figure 4. Tests for simple effects revealed that the organizational identification of participants who had undertaken a qualification rose, albeit not significantly, from Time $1(M=5.26, S D=0.09)$ to Time 2 $(M=5.48, S D=0.10)$, Wilks Lambda $=0.98, F(1,201)=3.1$, $p=0.08, \eta_{\mathrm{p}}^{2}=0.02$, but that the organizational identification of those who had not undertaken qualifications decreased, again not significantly, from at Time $1(M=5.47, S D=0.11)$ to Time 2 $(M=3.1, S D=0.10)$, Wilk Lambda $=0.99, F(1,201)=1.78$. $p=0.18, \eta_{\mathrm{p}}^{2}=0.009$.

The same analysis was also performed on participants' identification with clients. This revealed a similar pattern to that observed with care profession identification, however, there was no significant main effect for phase [Wilks Lambda $=0.99$, $F(1,201)=1.18, p=0.28]$ and no significant interaction effect between group and phase [Wilks Lambda $=0.99, F(1,201)=2.21$, $p=0.14]$.

In summary, our findings show that engaging in the professionalization process by acquiring a qualification served to increase carers' identification with the organization, and to maintain their identification with care professionals, but that not engaging in this process was associated with a reduction in both forms of identification. This accords with evidence from our pathway analysis where Model 2 suggests that undertaking a qualification leads to increased motivation and well-being outcomes because it serves to build organizational identification.

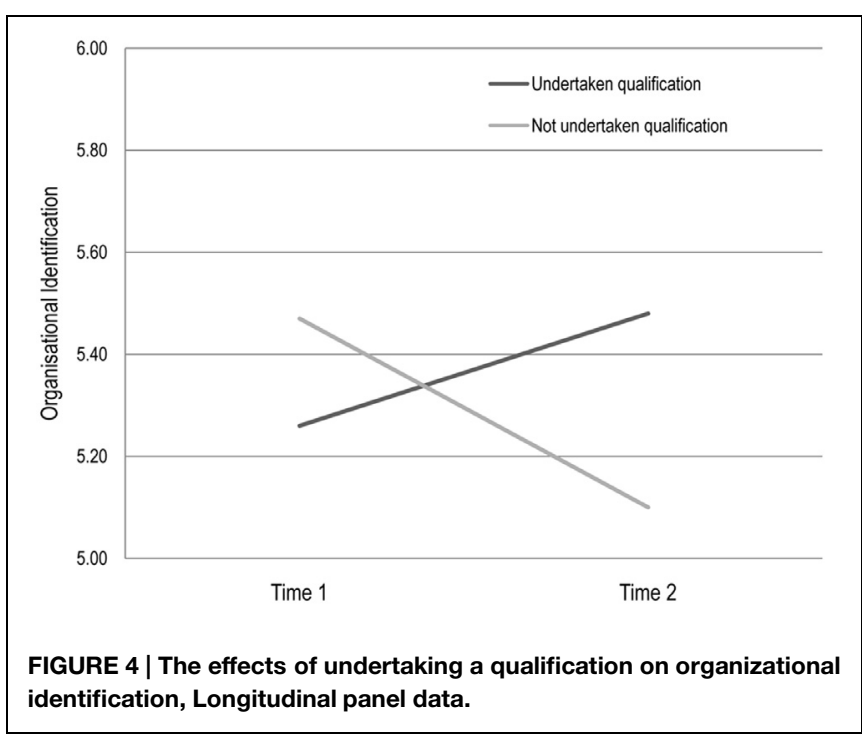




\section{Discussion}

The purpose of this study was to examine how care-workers' motivation and well-being is shaped by their social and relational identification at work. More specifically, the study sought to gain a better understanding of the ways in which care workers' motivation and well-being are structured (a) by material (pay) or virtuous (relationships with clients) reward, (b) by the working context (of residential vs. domiciliary care), and (c) by exposure to professionalization (through undertaking vs. not undertaking a qualification). It also sought to investigate the role of identity processes in accounting for the effects of these factors on the process of creating and sustaining compassionate work cultures in care organizations.

Based on a social identity theorizing, we argued that organizational identification provides a critical underpinning for sustainable motivation and well-being in the workplace (Ellemers et al., 2004; Jetten et al., 2012). Consequently, factors that serve to build or reinforce organizational identification (e.g., incentives or specific forms of training) should have a positive impact on individual motivations and well-being at work. At the same time, this analysis was supplemented by the proposal (gleaned from qualitative research; Bjerregaard et al., in press b) that for this particular workforce (and arguably many other 'helping' occupations) relational identification with clients' patients, or service users is central to the way in which workers define themselves within the broader organizational context. This suggestion also accords with previous research in the social identity tradition (Sluss and Ashforth, 2008; Sluss et al., 2012), which suggests that motivation and wellbeing should be particularly enhanced when these different bases of identification - relational and organizational align. Accordingly, we also examined the relationships between relational and organizational identifications and their combined role in supporting carer motivation and well-being.

\section{Summary of Findings}

Consistent with other studies undertaken with care workers (Skills for Care, 2007; Hussein et al., 2010; Atkinson and Lucas, 2012) participants in our study reported high levels of satisfaction and pride, and low levels of stress. Participants were motivated to work in care because of their relationships with clients, and they attached high value to training and personnel development, and to working conditions, but relatively low value to pay. In line with previous work (Van Dick, 2001; Haslam et al., 2003; Van Knippenberg et al., 2004; Riketta and Van Dick, 2005) and with H1, findings also showed that care workers' identification with different groups at work is positively related to their motivation and well-being. In particular, motivation and well-being were predicted both by identification with clients (H1a) and by organizational identification (H1b). As anticipated, care workers indicated higher levels of identification with clients than with the organization (H1c), but levels of motivation and well-being were best predicted by the latter (H1d).

\section{Effects of Incentives}

Findings from SEM confirmed that although care workers were primarily incentivised by 'love' (i.e., relationships with clients) rather than 'money' (i.e., pay), attaching value to either of these incentives was associated with increased motivation and well-being (H2a, H3a). Importantly, and consistent with our hypotheses, these relationships were also mediated by patterns of identification (H2b, H3b). Specifically, being incentivised by relationships with clients fed into motivation and wellbeing by increasing relational identification and, through this, organizational identification (H2c). A similar pattern was evident for incentivization by pay; however, here the mediating role of organizational identification was stronger (H3c).

Contrary to mainstream economic thinking about care work, these findings suggest that neither altruism nor money in themselves lead to more positive organizational outcomes. Rather, they contribute to enhanced motivation and well-being due largely to their ability to foster and reinforce care workers' organizational identification. Thus, rather than being particularly valued in its own right, pay can be seen to play an important role in motivating staff and making them feel good about themselves and their work because it helps build organizational identification - for example, by indicating to the individual that they are valued by the organization (Tyler and Blader, 2000). Likewise, enacting relationships with clients promotes motivation and well-being because this behavior reflects the way in which individuals see themselves within the organization. Indeed, the very weak fit of a model that represented the mainstream economic and individualistic perspectives wherein incentives directly affect motivation and well-being suggests that this oft-cited dichotomised explanation for work in this domain fails properly to explain key outcomes in this domain.

\section{Effects of Work Domain}

In line with $\mathrm{H} 4$, care workers' attachment to their job (i.e., a positive orientation to professionalization and low turnover intentions) was found to vary as a function of their working domain such that residential care workers displayed generally higher organizational motivation than domiciliary workers. Again, though, SEM indicated that these domainbased differences in motivation could again be accounted for by patterns of identification ( $\mathrm{H} 4 \mathrm{~b}$ and $4 \mathrm{c}$ ) in so far as the best fitting model was one in which differences in organizational identification mediated the relationship between work domain and motivation and well-being.

\section{Effects of Professionalization}

In line with other research into the effects of identification on training outcomes (Pidd, 2004; Bjerregaard et al., in press a), our findings indicate that undertaking a qualification increases well-being and attachment to one's job. However, consistent with our overall theoretical framework, these effects of training which we were able to examine longitudinally - could also be understood in terms of their consequences for organizational identification. Specifically, it appears that undertaking a 
qualification increased well-being and attachment because this reinforced individuals' sense of identification with their organization (H5a). Interestingly, although we predicted that organizational identification would be most important for explaining the effects of gaining a qualification, an alternative model that incorporated client identification as a precursor to organizational identification accounted for the data nearly as well. This pattern mirrors the pattern observed for incentivization and further underscores the important linkages between client-based and organizational identification in this domain.

\section{Theoretical Implications: Identity Convergence and the Creation of a Compassionate Workforce}

These findings corroborate and extend findings from previous organizational studies that have pointed to the positive mediating effects of organizational identification on motivational and wellbeing outcomes (see Van Knippenberg, 2000; Haslam et al., 2003; Ellemers et al., 2004; Ashforth et al., 2008; Jetten et al., 2012; van Dick and Haslam, 2012). In addition, this research considered the dynamic relationships between organizational identity and other work-based identities that operate at different levels of abstraction (Riketta and Nienaber, 2007; Sluss et al., 2012; Smith et al., 2012). In particular, we explored the relationship between relational identification with clients (or service users/patients) and organizational identification and found that client identification can become a basis for organizational identification, and accordingly that the forces that strengthen the former can also strengthen the latter with positive consequences for different aspects of organizational motivation and well-being.

Tests of alternative models that considered reversed sequences of mediators demonstrated poorer fit to the data, suggesting that although there is convergence between different forms of identification (i.e., relational and organizational), it is likely to be the former that builds the latter rather than the other way around. This may reflect the fact that because client identification operates at a relational level of identity it is "a linchpin in overall self-concept at work" (Sluss and Ashforth, 2008, p. 11). Drawing on findings from our previous qualitative work with care workers (Bjerregaard et al., in press b), this convergence between the specific relational identification and broader organizational identification is likely to occur through two processes. First, it may occur by means of 'affect transfer, whereby "affects generated from identifying with a role relationship directly and unconsciously transfer to the organization and vice versa" (Sluss and Ashforth, 2008, p. 5). That is, the positive affect generated from identifying with the carer role is transferred to the assessment of the organization in terms of its capability to care (both for clients and carers themselves; Bjerregaard et al., in press b). Second, it may also occur through the process of "behavioral sense-making" whereby "what one does, informs and confirms who one is" (Sluss and Ashforth, 2008 , p. 6). That is, enacting a carer role that one identifies with informs how one thinks both about oneself as a representative of the organization and about the organization as a whole.
In these ways, this study supports the notion that the different levels of care-worker identification (relational identification with clients and social identification with the organization) converge around care workers' perceptions that the organization values (a) their relationship with their clients, (b) the interests of the clients, and (c) the care workers themselves. At the same time it explains care workers' disengagement and frustration at the organization should they perceive it not to be acting in accordance with caring values. Accordingly, at least in the context of care work, it could be argued that the creation of a compassionate working culture depends upon the organization's capacity to both (a) to harness and support meaningful identities through which individuals understand their work and (b) to promote alignment between work-based identities at all levels (personal, relational, and organizational).

\section{Practical Implications}

At a practical level, this study helps us to see how the social identity approach can provide a multi-dimensional, dynamic framework through which to better understand care workers' motivation and well-being. First, by integrating the virtuous and financial aspects of caring - that is, by seeing both of these as reward that underpin workplace identities - this model challenges the simplistic view that care workers' motives are dichotomised between either 'love' or 'money.' Instead, it appears that care workers are motivated and buoyed by both 'love' of the caring relationships they have with their clients and 'money' as reflective of the caring relationship that exists between them and the organization for which they work. Second, this framework suggests that in order to be successful in building a compassionate culture in health and social care, attention needs to be paid to people's prevalent work-based relational and social identities (e.g., as argued by Haslam et al., 2003; Peters et al., 2013).

Amongst other things, these identities are created in conversations that draw on social, cultural, organizational and individual narratives, and which let people know who they are and why they matter (Harquail and King, 2010; Ibarra and Barbulescu, 2010; Bjerregaard, 2015). Accordingly, the values and behaviors that are attributed to these different identities can make them congruent and mutually supportive (e.g., seeing oneself to be both a caring professional and member of a caring organization) or can make them ambiguous, irrelevant and conflicting (e.g., seeing oneself as part of a family while at the same time being made to feel like a number and a commodity; Bjerregaard et al., in press b). The degree of alignment between multiple meaningful social identities in and out of work should also have consequences for sustained employee motivation. Hence, third, undertaking activities which support professionalization and embed compassionate practice are likely to motivate care workers and to make them feel good about both themselves and their work to the extent that these activities harness and develop meaningful organizational and relational identities that enable those workers to experience a congruence between the values and behaviors represented by different foci of social identification at work. 


\section{Conclusion}

This study provides detailed cross-sectional and longitudinal evidence of the way in which care workers' motivation is shaped by the dynamics of collective and relational identities at work. In this context, the application of the social identity approach has two key affordances. First, it allows us to understand the nuanced ways in which care workers are motivated and satisfied by both 'love' and 'money.' Second, it shows how these two things feed into increased motivation and well-being by building and maintaining meaningful work-based identities, in particular organizational identity. It thus appears that to the extent that particular incentives validate social identities at work, they will serve to make individuals more motivated to engage with their work and to feel better (both about themselves and their work) when they do. Conversely, when incentives negate valued identities, this is likely to result in detrimental outcomes for both the individual and the organization.

\section{References}

Adams, V., and Sharp, R. (2013). Reciprocity in caring labor: nurses' work in residential aged care in Australia. Fem. Econ. 19, 100-121. doi: 10.1080/13545701.2013.767982

Adamson, L., Dewar, B., Donaldson, J., Gentleman, M., Gray, M., Horsburgh, D., et al. (2012). Leadership in Compassionate Care Program. Edinburgh: Edinbrugh Napier University \& NHS Lothian.

Akerlof, G. A., and Kranton, R. E. (2010). Identity Economics: How Our Identities Shape Our Work, Wages, and Well-Being. Princeton, NJ: Princeton University Press.

Ashforth, B. E., Harrison, S. H., and Corley, K. G. (2008). Identification in organizations: an examination of four fundamental questions. J. Manage. 34, 325-374. doi: 10.1177/0149206308316059

Ashforth, B. E., and Mael, F. (1989). Social identity theory and the organization. Acad. Manage. Rev. 14, 20-39. doi: 10.2307/258189

Atkinson, C., and Lucas, R. (2012). Worker responses to HR practice in adult social care in England. Hum. Resour. Manage. J. 23, 296-312. doi: 10.1111/j.17488583.2012.00203.x

Beach, M. C., and Inui, T. (2006). Relationship-centered care: a constructive reframing. J. Gen. Intern. Med. 21, S3-S8. doi: 10.1111/j.1525-1497.2006.00302.x

Bjerregaard, K. (2015). The Shared Experience of Care: A Social Identity Approach to Understanding the Motivation of People Who Work in Social Care. Ph.D. thesis, The University of Exeter, Exeter. Available at: https://ore.exeter.ac.uk/ repository/handle/10871/16321

Bjerregaard, K., Haslam, S. A., and Morton, T. A. (in press a). How identification facilitates effective learning: the evaluation of generic versus localized professionalisation training. Int. J. Train. Dev.

Bjerregaard, K., Haslam, S. A., Morton, T. A., and Mewse, A. J. (in press b). The shared experience of caring: a study of care-workers' motivations and identifications at work. J. Ageing Soc.

Bowers, B. J., Fibich, B., and Jacobson, N. (2001). Care-as-service, careas-relating, care-as-comfort understanding nursing home residents' definitions of quality. Gerontologist 41, 539-545. doi: 10.1093/geront/41. 4.539

Cameron, C., and Moss, P. (2007). Care Work in Europe: Current Understandings and Future Directions. Hove: Psychology Press.

Care Quality Commission (2012). State of Care Report. London: Care Quality Commission.

Centre for Workforce Intelligence (2011). The Adult Social Care Workforce in England - Key Facts. London: Centre for Workforce Intelligence.

Crabtree, J. W., Haslam, S. A., Postmes, T., and Haslam, C. (2010). Mental health support groups, stigma, and self-esteem: positive and negative implications
In arriving at this conclusion, we believe the present research goes some way to addressing calls to "examine the team and organizational influences that contribute to compassionate care and determine how they can be strengthened" (Adamson et al., 2012, p. 32). It does so by confirming that compassionate behavior and values are enacted and sustained by care workers to the extent they make sense in terms of their salient social and relational identities. Accordingly, it appears that it is by recognizing, harnessing, and developing these identities that care organizations can encourage those they employ to play their part in enacting a culture of compassionate care.

\section{Acknowledgments}

Work on this paper was supported by grants from the Economic and Social Research Council and the Australian Research Council (FL110100199).

of group identification. J. Soc. Issues 66, 553-569. doi: 10.1111/j.15404560.2010.01662.x

Deci, E. L. (1972). Intrinsic motivation, extrinsic reinforcement, and inequity. J. Pers. Soc. Psychol. 22, 113-120. doi: 10.1037/h0032355

Department of Health (2006). The Dignity Challenge. London: Department of Health.

Department of Health (2012). Compassion in Practice: Nursing, Midwifery and Care Staff, Our Vision and Strategy. London: Department of Health.

Dewar, B., and Nolan, M. (2013). Caring about caring: developing a model to implement compassionate relationship centred care in an older people care setting. Int. J. Nurs. Stud. 50, 1247-1258. doi: 10.1016/j.ijnurstu.2013.01.008

Doosje, B., Ellemers, N., and Spears, R. (1995). Perceived intragroup variability as a function of group status and identification. J. Exp. Soc. Psychol. 31, 410-436. doi: 10.1006/jesp.1995.1018

Ellemers, N., De Gilder, D., and Haslam, S. A. (2004). Motivating individuals and groups at work: a social identity perspective on leadership and group performance. Acad. Manage. Rev. 29, 459-478. doi: 10.5465/AMR.2004.13670967

Ellemers, N. E., Spears, R. E., and Doosje, B. E. (1999). Social Identity: Context, Commitment, Content. San Fransico, CA: Blackwell Science.

Equality and Human Rights Commission (2012). Close to Home: An Inquiry into Older People and Human Rights in Home Care. London: Equality Human Rights Commission.

Gagné, M., and Deci, E. L. (2005). Self-determination theory and work motivation. J. Organ. Behav. 26, 331-362. doi: 10.1002/job.322

Garson, G. D. (2009). Structural Equation Modeling. Statnotes: Topics in Multivariate Analysis. Available at: http://www2.chass.ncsu.edu/garson/pa765/ statnote.htm

Greguras, G. J., and Diefendorff, J. M. (2009). Different fits satisfy different needs: linking person-environment fit to employee commitment and performance using self-determination theory. J. Appl. Psychol. 94, 465-477. doi: 10.1037/a0014068

Harquail, C. V., and King, A. W. (2010). Construing organizational identity: the role of embodied cognition. Organ. Stud. 31, 1619-1648. doi: $10.1177 / 0170840610376143$

Haslam, S. A. (2004). Psychology in Organizations: The Social Identity Approach, 2nd Edn. London: Sage.

Haslam, S. A. (2014). Making good theory practical: five lessons for an Applied Social Identity Approach to challenges of organizational, health, and clinical psychology. Br. J. Soc. Psychol. 53, 1-20. doi: 10.1111/bjso.12061

Haslam, S. A., Eggins, R. A., and Reynolds, K. J. (2003). The ASPIRe model: actualizing social and personal identity resources to enhance organizational outcomes. J. Occup. Organ. Psychol. 76, 83-113. doi: $10.1348 / 096317903321208907$ 
Haslam, S. A., Jetten, J., Postmes, T., and Haslam, C. (2009). Social identity, health and well-being: an emerging agenda for applied psychology. Appl. Psychol. 58, 1-23. doi: 10.1111/j.1464-0597.2008. 00379.x

Haslam, S. A., Powell, C., and Turner, J. C. (2000). Social identity, selfcategorization and work motivation: rethinking the contribution of the group to positive and sustainable organizational outcomes. Appl. Psychol. 49, 319-339. doi: 10.1111/1464-0597.00018

Haslam, S. A., and Reicher, S. (2006). Stressing the group: social identity and the unfolding dynamics of responses to stress. J. Appl. Psychol. 91, 1037-1052. doi: 10.1037/0021-9010.91.5.1037

Hayes, A. (2012). PROCESS: A Versatile Compulational Tool for Observed Variable Mediation, Moderation and Conditional Process Modelling. Available at: www. afhayes.com

Help the Aged (2007). My Home Life: Quality of Life in Care Homes. London: Help the Aged.

Heyes, A. (2005). The economics of vocation or 'why is a badly paid nurse a good nurse'? J. Health Econ. 24, 561-569. doi: 10.1016/j.jhealeco.2004. 09.002

Hu, L. T., and Bentler, P. M. (1999). Cutoff criteria for fit indexes in covariance structure analysis: conventional criteria versus new alternatives. Struct. Equ. Modeling 6, 1-55. doi: 10.1080/10705519909540118

Hussein, S., Stevens, M., and Manthorpe, J. (2010). International Social Care Workers in England: Profile, Motivations, Experiences and Future Expectations: Final Report. London: Social Care Workforce Research Unit.

Ibarra, H., and Barbulescu, R. (2010). Identity as narrative: prevalence, effectiveness, and consequences of narrative identity work in macro work role transitions. Acad. Manage. Rev. 35, 135-154. doi: 10.5465/AMR.2010. 45577925

Jetten, J., Haslam, C., and Haslam, S. A. (2012). The Social Cure: Identity, Health and Well-Being. Hove: Psychology Press.

Karlsson, L., and Rydwik, E. (2013). Doing care with integrity and emotional sensibility: reciprocal encounters in psychiatric community care of older people with mental health problems. Sociol. Mind 3, 185-192. doi: 10.4236/sm.2013.32025

Kenny, D. A. (2012). Structural Equation Modelling. Available at: www. davidakenny.net

Kovjanic, S., Schuh, S. C., Jonas, K., Quaquebeke, N. V., and Dick, R. (2012). How do transformational leaders foster positive employee outcomes? A selfdetermination-based analysis of employees' needs as mediating links. J. Organ. Behav. 33, 1031-1052.

Lepore, M. (2008). Care Workers' Motivation for Employment in Long-Term Care: Reconciling Inconsistencies. Athens, GA: Georgia State University.

Lim, C., and Putnam, R. D. (2010). Religion, social networks, and life satisfaction. Am. Sociol. Rev. 75, 914-933. doi: 10.1177/0003122410 386686

Lucas, R., Atkinson, C., and Godden, J. (2008). Employment Practices and Performance: Rewards, Incentives and their Relationship to Recruitment, Retention and Quality of Service in Adult Social Care in England. Manchester: Skills for Care.

Lucas, R., Atkinson, C., and Godden, J. (2009). Rewards and Incentives Research: Phase 2 Case Studies: Nursing Homes, Residential Homes and Domiciliary Care Establishments. Manchester: Skills for Care.

Maben, J., Adams, M., Peccei, R., Murrells, T., and Robert, G. (2012). 'Poppets and parcels': the links between staff experience of work and acutely ill older peoples' experience of hospital care. Int. J. Older People Nurs. 7, 83-94. doi: 10.1111/j.1748-3743.2012.00326.x

McDonald, R. P., and Ho, M. H. R. (2002). Principles and practice in reporting structural equation analyses. Psychol. Methods 7, 64-82. doi: 10.1037/1082989X.7.1.64

Nelson, J. A., and Folbre, N. (2006). Why a well-paid nurse is a better nurse. Nurs. Econ. 24, 127-130.

Nolan, M. R., Brown, J., Davies, S., Nolan, J., and Keady, J. (2006). The Senses Framework: Improving Care for Older People through A Relationship-Centred Approach. Getting Research into Practice (GRiP) Report No 2. Sheffield: University of Sheffield.

Oakes, P. J., Haslam, S. A., and Turner, J. C. (1994). Stereotyping and Social Reality. Oxford: Blackwell.
Onorato, R., and Turner, J. (2001). "The "I," the "Me," and the "Us": the psychological group and self-concept maintenance and change," in Individual Self, Relational Self, Collective Self, eds C. Sedikides and M. B. Brewer (Philadelphia, PA: Psychology Press), 147-170.

Onyett, S. (2012). Creating a culture to deliver compassionate care. Nurs. Times $108,12$.

Peters, K., Haslam, S. A., Ryan, M. K., and Fonseca, M. (2013). Working with subgroup identities to build organizational identification and support for organizational strategy: a test of the ASPIRe model. Group Organ. Manag. 38, 128-144. doi: 10.1177/1059601112472368

Pidd, K. (2004). The impact of workplace support and identity on training transfer: a case study of drug and alcohol safety training in Australia. Int. J. Train. Dev. 8, 274-288. doi: 10.1111/j.1360-3736.2004.00214.x

Riketta, M., and Nienaber, S. (2007). Multiple identities and work motivation: the role of perceived compatibility between nested organizational units. Br. J. Manag. 18, S61-S77. doi: 10.1111/j.1467-8551.2007. 00526.x

Riketta, M., and Van Dick, R. (2005). Foci of attachment in organizations: a meta-analytic comparison of the strength and correlates of workgroup versus organizational identification and commitment. J. Vocat. Behav. 67, 490-510. doi: 10.1016/j.jvb.2004.06.001

Ryan, R. M., and Deci, E. L. (2000). Self-determination theory and the facilitation of intrinsic motivation, social development, and well-being. Am. Psychol. 55, 68-78. doi: 10.1037/0003-066X.55.1.68

Skills for Care (2007). National Survey of Care Workers. Leeds: Skills for Care.

Skills for Care (2012). The Size and Structure of the Adult Social Care Sector and Workforce in England. Leeds: Skills for Care.

Skills for Care (2013a). The Impact of Qualifications on the Adult Social Care Workforce. Leeds: Skills for Care.

Skills for Care (2013b). Why are Some Employees more Successful than Others in Retaining Their Workforce?. Leeds: Skills for Care.

Skills for Care (2013c). The Economic Value of the Adult Social Care Sector in England. Leeds: Skills for Care.

Sluss, D. M., and Ashforth, B. E. (2008). How relational and organizational identification converge: processes and conditions. Organ. Sci. 19, 807-823. doi: 10.1287 /orsc. 1070.0349

Sluss, D. M., Ployhart, R. E., Cobb, M. G., and Ashforth, B. E. (2012). Generalizing newcomers' relational and organizational identifications: processes and prototypicality. Acad. Manag. J. 55, 949-975. doi: 10.5465/amj. 2010.0420

Smith, L. G., Amiot, C. E., Callan, V. J., Terry, D. J., and Smith, J. R. (2012). Getting new staff to stay: the mediating role of organizational identification. Br. J. Manag. 23, 45-64.

Tajfel, H., and Turner, J. C. (1979). “An integrative theory of intergroup conflict,” in The Social Psychology of Intergroup Relations, eds W. G. Austin and S. Worchel (Monterey, CA: Brooks/Cole), 33-47.

Turner, J. C. (1985). Social categorization and the self-concept: a social cognitive theory of group behavior. Adv. Group Process. 2, 77-122.

Turner, J. C., Hogg, M. A., Oakes, P. J., Reicher, S. D., and Wetherell, M. S. (1987). Rediscovering the Social Group: A Self-Categorization Theory. Oxford: Basil Blackwell.

Tyler, T. R., and Blader, S. L. (2000). Cooperation in Groups: Procedural Justice, Social Identity, and Behavioral Engagement. Philadelphia, PA: Psychology Press.

Ullman, S. E. (1996). Correlates and consequences of adult sexual assault disclosure. J. Interpers. Violence 11, 554-571. doi: 10.1177/088626096011004007

Van Dick, R. (2001). Identification in organizational contexts: linking theory and research from social and organizational psychology. Int. J. Manag. Rev. 3, 265-283. doi: 10.1111/1468-2370.00068

van Dick, R., and Haslam, S. A. (2012). "Stress and well-being in the workplace: support for key propositions from the social identity approach," in The Social Cure: Identity, Health, and Well-Being, eds J. Jetten, C. Haslam, and S. A. Haslam (Hove: Psychology Press), 175-194.

Van Knippenberg, D. (2000). Work motivation and performance: a social identity perspective. Appl. Psychol. 49, 357-371. doi: 10.1111/1464-0597.00020

Van Knippenberg, D., De Dreu, C. K., and Homan, A. C. (2004). Work group diversity and group performance: an integrative model and research agenda. J. Appl. Psychol. 89, 1008-1022. doi: 10.1037/0021-9010. 89.6.1008 
Wegge, J., Van Dick, R., Fisher, G. K., Wecking, C., and Moltzen, K. (2006). Work motivation, organizational identification, and well-being in call centre work. Work Stress 20, 60-83. doi: 10.1080/02678370600 655553

Wild, D., Szczepura, A., and Nelson, S. (2010). Residential Care Home Workforce Development: The Rhetoric and Reality of Meeting Older Residents' Future Care Needs. London: Joseph Rowntree Trust.

Wilson, C. B., Davies, S., and Nolan, M. (2009). Developing personal relationships in care homes: realising the contributions of staff, residents and family members. Ageing Soc. 29, 1041-1063. doi: 10.1017/S0144686X0900840X
Conflict of Interest Statement: The authors declare that the research was conducted in the absence of any commercial or financial relationships that could be construed as a potential conflict of interest.

Copyright (c) 2015 Bjerregaard, Haslam, Morton and Ryan. This is an open-access article distributed under the terms of the Creative Commons Attribution License (CC BY). The use, distribution or reproduction in other forums is permitted, provided the original author(s) or licensor are credited and that the original publication in this journal is cited, in accordance with accepted academic practice. No use, distribution or reproduction is permitted which does not comply with these terms. 